\title{
Medical Products Supply Chain and Its Information System Design
}

\author{
Hong Sun ${ }^{1}$, Xiaoyu Chen² \\ ${ }^{1}$ School of Computer Science, Yangtze University, Jingzhou, China \\ ${ }^{2}$ College of Civil and Architectural Engineering, North China University of Science and Technology, Tangshan, China \\ Email: sunhong@yangtzeu.edu.cn
}

How to cite this paper: Sun, H. and Chen, X.Y. (2019) Medical Products Supply Chain and Its Information System Design. Yangtze Medicine, 3, 142-148. https://doi.org/10.4236/ym.2019.32014

Received: May 23, 2019

Accepted: June 25, 2019

Published: June 28, 2019

Copyright (c) 2019 by author(s) and Scientific Research Publishing Inc. This work is licensed under the Creative Commons Attribution International License (CC BY 4.0).

http://creativecommons.org/licenses/by/4.0/

\begin{abstract}
This paper introduces the supply mode of medical products, and analyzes the development trend of medical products supply enterprise in China. From the aspects of basic management, resource integration and database design, we put forward the design concept of the informationization of the supply chain system of medical products in China. The information system can ensure the precision and rationality of the supply of medical products, and provide high-quality services and service efficiency, and meet the different needs of different customers.
\end{abstract}

\section{Keywords}

Medical Products Supply Chain, System Design, Informationization, Design

\section{Introduction}

With the development of society and the advancement of science and technology, enterprise supply chain management has become an important factor to enhance the competitiveness of enterprises in the market. In some way, comparing with foreign enterprises, China's medical product supply enterprises have a large gap, therefore, it is more necessary to informationize the supply chain, reduce circulation links, solve the problem of medical product supply effectively, and serve patients better.

\section{Supply Mode of Medical Products}

\subsection{Supply Mode of Medical Products in China}

The supply of medical products in China involves manufacturers, wholesalers, retailers, medical institutions, patients and so on, the supply channels are dif- 
ferent, the way may be the manufacturer-wholesalers-retailers-medical institutions-patients, it is also possible to be manufacturer-medical institutions-patients, may also be manufacturers-retailers-patients. Because medical products reach patients from different channels, their prices are not the same, and the quality is difficult to guarantee, and it increases the difficulty of supervision.

There are many medical products enterprises in China. But most of them are small, scattered and random distribution. At the same time, the informationization and standardization of medical products logistics are relatively backward. Although many medical products suppliers, retailers and the hospital pharmacy are equipped with computers, but most of them did not use the logistics information system, information is not shared. They play a limited role; therefore it is far from the requirements of the logistics operation [1]. The traditional supply mode of medical products presents the characteristics of high investment and high risk. Poor logistics infrastructure construction, low level of informationization, and a lack of supervision in transportation and distribution links [2], results in that patients bear high drug prices and manufacturers get a low profit. At the same time, the traditional mode of supply cannot provide information to manufacturers about the use of medical products timely, and wholesalers at all levels as an important link in the supply chain also can not adjust the stock of drugs timely. Therefore, the establishment of an efficient supply chain information management system is the general trend.

\subsection{Supply Mode of Medical Products Abroad}

After decades of development, foreign medical products supply model has been quite mature and standardized. In Europe, America and Japan and other developed countries, medical products supply enterprises have achieved large-scale development. Some super medical products circulation chain groups occupy a monopoly position, account for the majority of market share, and play a leading role in the buyer's market [3].

As the development of network technology, chain stores spring up, e-commerce network marketing gets rapid development at the same time, as shown in Figure 1.

Therefore, we can refer to the successful experience of foreign medical products supply model which will also be the future development trend of China's medical products supply.

Foreign successful medical products supply enterprises have accumulated rich

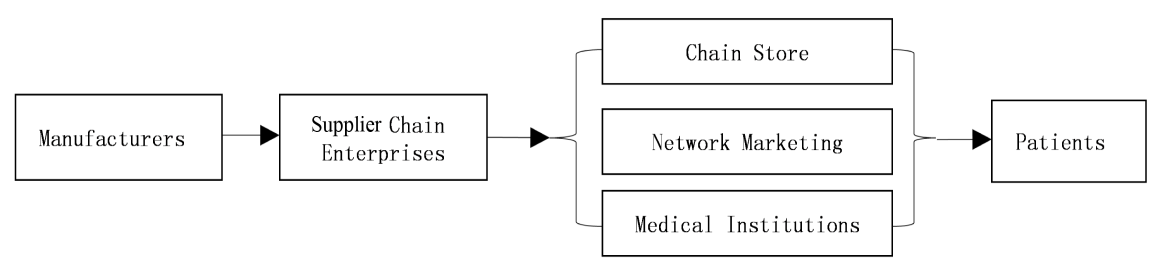

Figure 1. Medical products chain group. 
experience in the market competition, at the same time they have obvious advantages as follows:

1) A globally integrated procurement model. In order to obtain a competitive advantage in procurement costs, most multinational enterprises make a purchase through large group or group joint in the global scope in recent years. It can reduce procurement costs greatly. And the results are remarkable, it's difficult for some small enterprises to maintain independently, and they have to attach to large groups or be merged.

2) High quality service. After decades of market operation, foreign successful medical products supply enterprises have accumulated a series of service concepts. They have rich experience about customer relations, consumer psychological research, market analysis and other aspects. They have changed from simple price competition to a higher level of service competition. To improve customer loyalty, and expand market share, they give full play to the comprehensive advantages of services, efficiency, quality, price and so on.

3) Advanced management concepts. Through scientific management, the advanced management ideas such as process management, target management, people-oriented management and other are introduced. At the same time, to improve the overall operating efficiency, supply chain, modern logistics, e-commerce and other technical means have been used.

High efficiency, low cost and high quality service level determine the leading position of foreign enterprises in comprehensive competitiveness.

\section{Analysis on the Development Trend of Medical Products Supply Enterprise in China}

\subsection{Supply Links Will Become More and More Important}

With the development of network and electronic communication technology, medical products suppliers will not be canceled but also become more and more important. At present, medical products suppliers make profits mainly on the basis of the purchase price. In the future, the situation will gradually change. Medical device manufacturers, suppliers and medical institutions will have more opportunities and needs for close cooperation than ever before, forming a closely integrated supply chain system, which is completely able to achieve a virtuous circle that benefits both hospitals and suppliers. On the one hand, long-term stable cooperative relationship can be formed by simplifying transaction process, reducing communication cost and improving information transparency. On the other hand, hospitals can expand the purchase volume to improve their bargaining power, reduce the total purchase price and shorten the payment cycle by integrating the demand for centralized procurement, so as to reduce the financial pressure on suppliers [4].

\subsection{Gross Profit Rate of Medicines Products Continues to Decline}

The prices of medical products have been slashed many times in our country. 
The comprehensive gross profit rate has fallen to $8 \%$ or so [5].

\subsection{Supply Enterprises Will Be Bigger and Bigger}

Small enterprises will gradually disappear through bankruptcy, mergers and acquisitions, restructuring and other means. Wholesalers will gradually be transformed into agents [6]. Agent distribution system will become the main mode of medical products supply. The number of supply enterprises will be significantly reduced. The distribution capacity of a single enterprise will become very strong, and the distribution variety will be very complete. Logistics distribution means will be more and more modern, and realize electronic information.

\subsection{Service Level Will Become an Important Competition Factor}

At present, the price is still the main competition means for medical products supply enterprises. In future the competition will include service, convenience, quality, price and so on. The service will be in the first place, and the price will be at the bottom. In order to provide better service, medical products producer, supplier, and user will form a closer and closer alliance through application of e-commerce platform.

\section{Design of Informatization of Medical Products Supply Chain System}

\subsection{Basic Management}

In the basic management stage of medical product supply chain informationization, enterprises need to standardize the basic business process, construct the basic resource system, and realize the informationization of the system at the same time. The informationization of basic resource system includes price management, decision management, quality management, wholesale business management and logistics distribution management etc. [7].

\subsection{Resource Integration}

Through the further improvement of basic management, medical product enterprises put forward higher informatization requirements for integrated enterprise resource management. For example, in the phase of enterprise resource integration the following two points can be carried out: first, strengthen the application of business information system, personnel information system, and so on. Each information system exists in a separate form. How to integrate them and maximize the use of them is a problem that people need to face. Second, under normal circumstances, if the supply chain management model is used, how to ensure the safety and accuracy of data sharing is another problem to be faced in the stage of resource integration.

\subsection{Database Design}

Database design should be combined with the design and development of the 
application system. It includes six stages: demand analysis, conceptual structure design, logical structure design, physical structure design, database implementation, database operation and maintenance.

1) Demand analysis

The task of this stage is to make clear the various needs of users through detailed investigation, understand the existing management information system, fully consider the effective use of existing data, determine the objects to be managed in the information system, and form a demand analysis manual for the next design reference.

2) Conceptual structure design

The task of this stage is: draw the E-R diagram according to the demand analysis manual.

3) Logical structure design

The task of this stage is to transform the E-R diagram into a logical structure model supported by the specific database management system.

4) Physical structure design

The task of this stage is to choose a physical structure that best meets the application requirements on the basis of the designed logical model. Physical structure design depends on the given computer hardware environment, software environment and database management system. Because the current relational database is the most common, one of the SQL Server, Oracle, MySQL databases can be used [8].

5) Database implementation

The task of this stage is: according to the logical structure design and the physical structure design result, establishes the database on the selected DBMS, prepares the application program, loads the experimental data and tests the application program, discovers the question then to do the corresponding processing.

6) Database operation and maintenance

The database can be put into practice after trial operation. However, as the application environment is constantly changing, it is an essential task to evaluate, adjust and modify the database design.

Medical products supply chain includes manufacturers, medical products, warehouses, logistics distribution center, medical institutions and other entities. While designing the database, first, a table is created for each entity, and a primary key is determined for each table. Then according to the needs of management, relationships between tables are created. The E-R diagram for the database is shown in Figure 2.

The database can share data, reduce data redundancy, maintain data independence, and realize centralized control of data to ensure the safety and accuracy of data. In addition, it should also pay attention to the maintenance of relevant data in the database to further ensure the safety and reliability of data. 


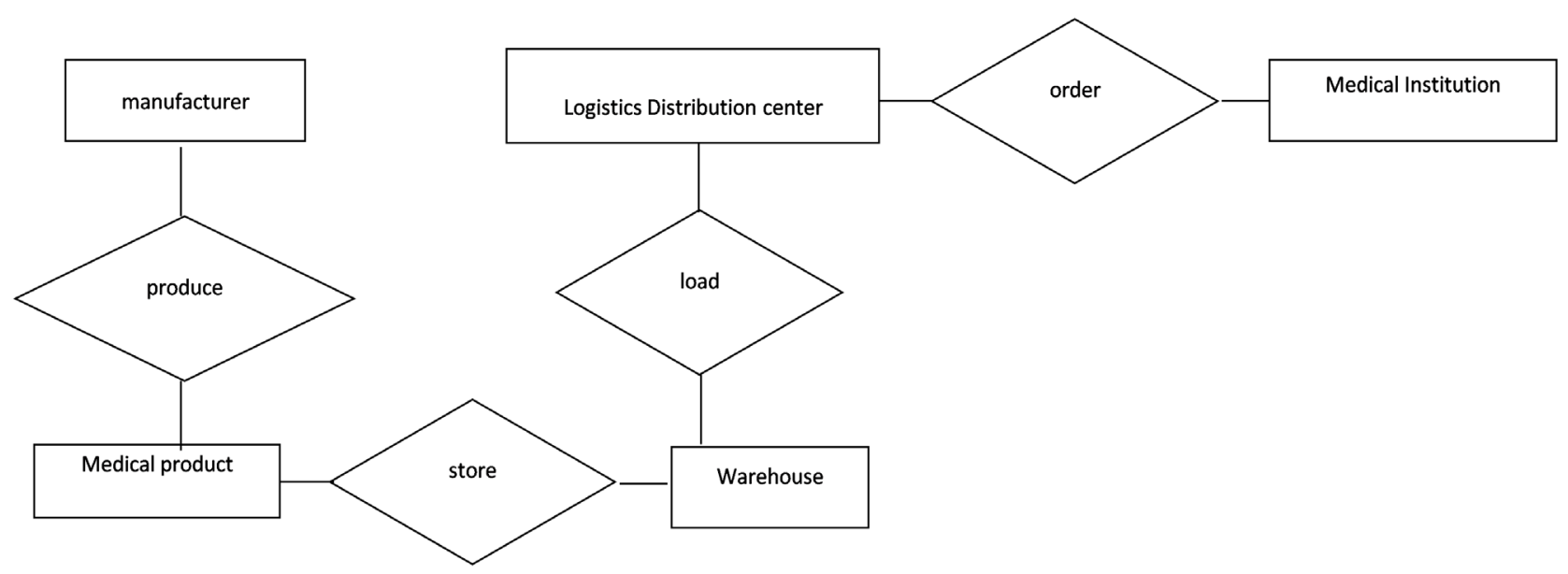

Figure 2. The E-R diagram for the database.

\section{Conclusion}

In a word, if medical products' suppliers want to get better development in the context of rapid social progress, they need to realize informatization of the supply chain. The informationization of supply chain can provide customers with high quality service and efficiency, and meet the different needs of different customers. At the same time, the application of advanced technology in various management task can ensure the accuracy and rationality of medical products supply. The informationization design of medical products supply chain system is a huge project, which requires not only the rational allocation of resources and the improvement of service quality, but also the design, management and maintenance of database.

\section{Conflicts of Interest}

The authors declare no conflicts of interest regarding the publication of this paper.

\section{References}

[1] Li, W.J. (2017) Medical Logistics in Our Country Development Present Situation and Existing Problems of Analysis. China's Health Industry, No. 11, 196-198.

[2] Deng, Z.H. (2017) The Differences between Chinese and Foreign Medicine Cold Chain Logistics Development and Experience for Reference. Foreign Trade Practice, No. 6, 89-92.

[3] Shao, L. and Xue, J. (2007) Comparison and Innovation Research of Chinese and Foreign Medical Logistics Business Models. Dalian Maritime University, Dalian.

[4] The Supplier Learning Group, the Medical Supplier, Is Facing Three Profound Changes. https://cloud.tencent.com/developer/news/313248

[5] Zhu, H.B. (2019) Marketing of Modern Medicine. https://max.book118.com/html/2019/0122/5243323122002003.shtm

[6] Anonymous (2019) Soft Crown Group Pharmaceutical Circulation Information Solutions-Medical and Health Solutions. 
http://www.docin.com/p-1144874812.html

[7] Sun, T. (2019) Discussion on Supply Chain Information Management of Pharmaceutical Commercial Enterprises. Accounting Studies, No. 1, 193, 195.

[8] Anonymous (2019) Describe Three Common Relational Databases. https://wenda.so.com/q/1461751207728934 